\title{
PROCESSO GRUPAL E A QUESTÃO DO PODER EM MARTÍN-BARÓ
}

Sueli Terezinha Ferreira M artins

UNESP. Bauru

RESU M 0: 0 presente artigo trata da concepção de processo grupal e poder social enfocada por $\mathrm{M}$ artín-Baró. ${ }^{1} \mathrm{O}$ autor retoma a concepção de grupo presente no trabalho de Sílvia Lane, quando considera os aspectos pessoais, as características grupais, a vivência subjetiva e realidade objetiva e 0 caráter histórico do grupo. $\mathrm{N}$ a perspectiva da psicologia social, segundo o autor, é muito mais relevante a análise do papel do poder na vida cotidiana, no dia-a-dia das pessoas, do que se centrar nos acontecimentos excepcionais e não rotineiros. Considerando que grande parte da prática profissional do psicólogo, principalmente numa perspectiva psicossocial, envolve o trabalho com grupos, a abordagem da questão do poder passa a ter papel fundamental. N este sentido, o contato com a produção de M artín-Baró é essencial e pode contribuir incisivamente no nosso trabalho cotidiano.

PALAVRAS-CH AVE: processo grupal, poder social, ação humana, abordagem psicossocial crítica.

\section{GROUP PROCESS AND THE POWER ISSUE IN MARTÍN - BARÓ}

ABST RACT: The present article discusses the group process and the social power conceptions focused by M artín-Baró. The author retakes the group conception present in Sílvia Lane's work, when it considers the personal aspects, the group characteristics, the subjective existence and objective reality and the historical character

1 M artín-Baró viveu em El Salvador. Foi jesuíta, teólogo e psicólogo social. Foi assassinado em 16 de novembro de 1989 por soldados do governo de El Salvador. Comprometido politicamente com a população mais pobre, atuou e publicou vários trabalhos sobre o povo latino-americano. 
of the group. In the perspective of the social psychology, according to the author, it is much more important the analysis of the role of the power in the daily life, in the people's day by day, which implies routine events than to center it in the exceptional ones. Considering that great part of the psychologist's professional practice, mainly in a psychosocial perspective, involves the work with groups, the power issue approach starts to have a fundamental role. In this sense, the contact with Martín-Baró's production is essential and it can contribute to our daily work incisively.

KEYWORDS: group process, social power, human action, critical psychosocial approach.

\begin{abstract}
À força [G ewalt], costuma-se associar a idéia dealgo que seencontra próximo epresente. Ela émais coercitiva e imediata do que o poder [M acht]. Falase, enfatizando-a, em força física. 0 poder, em seus estági os mais profundos eanimais, éantes força. ... 0 poder émaisuniversal emaisamplo; elecontém muito mais, e já não é tão dinâmico. É mais cerimonioso e possui atéum certo grau de paciência.
\end{abstract}

(CANETTI, 1960/1995:281)

Em geral os autores definem grupo como sendo uma unidade que se dá quando os indivíduos interagem entre si e compartilham al gumas normas e objetivo. M uitos são os aspectos indicados como relevantes para diferenciar um grupo de outras situações em que verificamos a presença de várias pessoas em uma mesma atividade.

M artín-Baró (1989), ao abordar a temática, faz menção ao trabalho de Lane (1984), reafirmando alguns aspectos apontados na concepção de grupo apresentada pela autora, quando considera os aspectos pessoais, as características grupais, a vivência subjetiva e realidade objetiva e o caráter histórico do grupo.

N este sentido, tanto Lane (1984) quanto M artín-Baró falam em processo grupal e não em grupo ou dinâmica de grupo. $N$ ão se 
trata apenas de diferença na denominação mas uma diferença profunda no fenômeno estudado. Ao falar em processo os autores re metem ao fato do próprio grupo ser uma experiência histórica, que se constrói num determinado espaço e tempo, fruto das relações que vão ocorrendo no cotidiano, e ao mesmo tempo, que traz para a experiência presente vários aspectos gerais da sociedade, expressas nas contradições que emergem no grupo:

0 grupo tem sempre uma dimensão de realidade referida a seus membros e uma dimensão mais estrutural, referida à sociedade em que se produz. Ambas dimensões, a pessoal e a estrutural, estão intrinsecamente ligadas entre si.

(M ARTÍN -BARÓ, 1989:207)

O caráter histórico do grupo é apontado por Lane (1984) quando afirma que "o significado da existência e da ação grupal só pode ser encontrado dentro de uma perspectiva histórica que considere a sua inserção na sociedade, com suas determinações econômicas, institucionais e ideológicas ( $p .81$ )". 0 mesmo aspecto será evidenciado posteriormente na obra de Martín-Baró, que, em função desta contextualização, propõe uma teoria dialética sobre o grupo humano. Isso implica em compreender que na sociedade atual, o grupo na sua singularidade, expressa múltiplas determinações e as contradições presentes no capitalismo. Alguns desdobramentos dessa relação são as contradições entre: individual/social; competição/interdependência; ter/não ter recursos (materiais, culturais e/ou pessoais) para submeter o outro aos seus interesses (exploração); dependência/independência.

Coerente com essa perspectiva, a proposta de M artín-Baró (1989) se constrói a partir de uma análise crítica sobre as teorias grupais, quando ele aponta três grandes problemas da maioria dos modelos utilizados pela psicologia social: "a) a parcialidade dos paradigmas predominantes; b) a perspectiva individualista; e c) 0 ahistoricismo" (p.203). A tendência da psicologia social em trabaIhar com grupos na perspectiva dos pequenos grupos; ênfase nos 
elementos subjetivos das relações; e abstração dos indivíduos ou dos grupos de sua história, levando a uma naturalização das realidades grupais, representam os principais problemas acima citados.

Para superar os problemas relatados, são três condições que uma teoria dialética sobre o grupo humano deve reunir:

a) Deve dar conta da realidade social do grupo enquanto tal, realidade não redutível às características pessoais dos indivíduos que constituem o grupo. [...]

b) D eve ser o suficientemente compreensiva para incluir tanto os pequenos grupos como os grandes grupos. [...]

c) D eve incluir como um de seus aspectos básicos o caráter histórico dos grupos humanos.

(M ART ÍN -BARÓ, 1989:205-6)

Tendo como base essas três condições, 0 autor define grupo enquanto "uma estrutura de vínculos e relações entre pessoas que canaliza em cada circunstância suas necessidades individuais e/ou interesses coletivos" (p.206). Ressalta ainda que um grupo é uma estrutura social: é uma realidade total, um conjunto que não pode ser reduzido à soma de seus membros. "A totalidade do grupo supõe alguns vínculos entre os indivíduos, uma relação de interdependência que é a que estabelece 0 caráter de estrutura e faz das pessoas membros" (Idem). Assim, segundo o autor, um grupo constitui um canal de necessidades e interesses em uma situação e circunstância específica, afirmando com isso o caráter concreto, histórico de cada grupo. A presenta ainda, três parâmetros principais para a análise do processo grupal:

1) A identidade do grupo, ou seja, a definição do que é e o caracteriza como tal frente a outros grupos; 2) o poder de que dispõe o grupo em suas relações com os demais grupos e, 3) a atividade grupal e mais a significação social do que produz essa atividade grupal (1989, p. 208) [grifos do autor].

Três aspectos devem ser considerados na conformação da identidade de um grupo:

- formalização organizativa: determinação das condições de pertencer ao grupo (normas formais ou informais, rígidas ou flexíveis, está- 
veis ou passageiras); requer ainda uma definição de suas partes e uma regulação das relações entre elas (divisão ou não das funções, sistematização das tarefas, distribuição de trabalho e atribuições);

- as relações com outros grupos: a dialética intergrupal produzida historicamente em cada sociedade interfere no surgimento do grupo, assim como a sua conexão com as necessidades e os interesses de uma classe social;

- a consciência de pertencer a um grupo: o grupo passa a ser para o indivíduo uma referência para sua própria identidade ou vida, referência essa criada a partir do sentimento de pertença subjetiva a um grupo. Este sentimento é que contribui para que um grupo de pessoas se sintam e atuem como grupo, possibilitando a sua identificação.

Com relação ao poder de um grupo, o autor coloca que ele "é aquele diferencial favorável de recursos que se estabelece quando se relaciona com outros grupos em função de alguns objetivos, e que permite fazer avançar seus interesses na convivência social" (1989, p.227). Como esta temática é fundamental em nosso trabalho, voltaremos a ela posteriormente, para apresentar com mais detalhes como a questão do poder é trabalhada por M artín-Baró.

0 último parâmetro apontado por M artín-Baró para analisar um grupo é sua atividade: "Q ue atividade ou atividades desenvolve? Q ual é o produto de seu fazer?" (p.217). A atividade grupal tem duas dimensões: externa, relacionada com a sociedade e/ou outros grupos, quando o grupo deve ser capaz de produzir um efeito real sobre eles para afirmar sua identidade, e interna, vinculada aos membros do próprio grupo, em direção à realização dos objetivos que levem em consideração as aspirações individuais ou comuns.

A presença da categoria atividade traz uma explicação teórica importante para a psicologia social subsidiada por pressupostos marxianos, que é o fato de depender essencialmente do modo de vida, que é determinado pelas relações sociais existentes e pela posição social que o indivíduo ocupa nestas relações. M artín-Baró (1997) afirma que 0 trabalho constitui a atividade humana mais relevante na definição do sentido da existência humana, pois sua vida se articula ao redor do trabalho. 0 indivíduo dedica muito tempo da sua vida para preparar-se para o trabalho, assim como para realizá-lo. É 
através do seu trabalho ou do trabalho das pessoas com quem convive, que se organizam o tempo e a distribuição de suas outras atividades, inclusive as atividades grupais.

Assim, a categoria atividade ganha uma dimensão importante no processo grupal, como ponto de partida para o desenvolvimento das outras dimensões intrínsecas a esse processo. D este modo, M artín-Baró defende que

I dentidade, poder e atividade não são aspectos grupaisindependentes [... em cada situação concreta os grupos se encontram imbricados, diretamente ou através de seus membros, o que gera identidades grupais parcialmente comunsou difusas, poderescompartilhados e ações com efei tos múlti plos.

(M ARTÍN-BARÓ, 1989: 227)

TIPOS DE GRUPOS: PRIMÁRIOS, FUNCIONAIS E ESTRUTURAIS

M artín-Baró (1989) utiliza-se das dimensões de identidade, poder e atividade grupal, para diferenciar os grupos primários, funcionais e etruturais, "correspondentes à relações sociais do mesmo tipo que articulam o 'fazer' social das pessoas" (p.227). Partindo dessas dimensões, o que caracteriza o grupo primário, o funcional e 0 etrutural?

Nos grupos primários o produto das relações sociais (o 'fazer' social) é a satisfação das necessidades básicas da pessoa e a formação de sua identidade. D este modo, o que caracteriza o grupo primário são os vínculos interpessoais (identidade), as características pessoais (poder) e a satisfação de necessidades pessoais (atividade grupal). $M$ artín-Baró acrescenta que muitas vezes confunde-se pequeno grupo como sinônimo de grupo primário. $\mathrm{Na}$ verdade nem todo grupo pequeno é um grupo primário. Basta darmos uma pequena olhada na maioria dos grupos formados na sociedade atual para verificarmos que de fato a maior parte deles não se caracteriza como primário, pois centra-se fundamentalmente em aspectos pontuais e parciais da vida de seus participantes. Conforme nos aponta 0 autor, 
Q uatro fatores podem influir na formação espontânea de um grupo primário: a) a atração entre seus membros; b) alguma semeIhança entre eles; c) a ansiedade; d) a complementaridade de suas características pessoais [...] A própria atividade dos grupos primários vai gerando vínculos afetivos e de complementaridade funcional entre os membros, tornando-os mais interdependentes, até o ponto de modelar as necessidades e ainda a identidade pessoal de cada um.

(MART ÍN -BARÓ, 1989:305-6)

Portanto, pequenos grupos cuja formação não se baseia em vínculos interpessoais, resultantes da atração entre seus membros pelo processo de identificação por semelhanças e de complementaridade de suas características, não se originam como grupos primários. Exemplos disso são os grupos de encontro e os de entretenimento que se centram "em relações dos membros do grupo 'aqui e agora', em um ambiente permissivo e não diretivo" (p.305). São grupos que não encarnam uma história comum e raízes sociais, não podendo, portanto, ser considerados como grupos primários.

A maioria dos pequenos grupos existente na sociedade caracteriza-se na verdade, como grupo funcional, pois sua identidade é construída pelo papel social que o indivíduo desempenha, sendo 0 poder centrado geralmente na capacitação e na ocupação social de seus membros, tendo, portanto, como eixo de sua atividade grupal a satisfação de necessidades sistêmicas e não pessoais como ocorre no grupo primário. O s grupos existentes na escola são exemplos de grupos funcionais: grupo de professores, grupos na sala de aula, conselho de classe, grêmio estudantil, etc. 0 mesmo pode-se dizer dos grupos formados em unidades de saúde, como por exemplo, de gestantes, de técnicos, de familiares, de usuários com transtornos neuróticos, grupo de pessoas com doenças crônicas. Assim, nas palavras do autor:

Os grupos funcionais são aqueles que correspondem à di vi são do trabalho no interior deum determinado sistema social. Se trata, por conseguinte, depessoasque cumprem a mesma função com respei to a um sistema, pessoas que têm os mesmospapés eocupam uma posição equivalente. 0 poder dos grupos 
Martins, S. T. F.; "Processo grupal e a questão do poder em Martín-Baró"

funcionais enquanto tais depende do valor ou importância queo seu trabalho tenha em uma sociedade[... ]

(M ART ÍN -BARÓ, 1989:225)

A partir dessa definição verificamos que uma característica básica dos grupos funcionais é que eles referem-se apenas a aspectos parciais da vida de seus membros, o que pode produzir em algumas situações conflitos entre os diferentes papéis que desempenham os indivíduos participantes desses grupos.

$\mathrm{N}$ a verdade, o que podemos notar é que, desde a infância até a fase adulta, participamos prioritariamente de grupos funcionais, seja na escola, na igreja, no trabalho, e mesmo em atividades aparentemente de lazer, como um grupo esportivo ou musical. Por outro lado, a nossa vinculação a grupos primários é restrita a poucos grupos no decorrer de toda a vida. Também não podemos deixar de apontar a possibilidade de um grupo originalmente funcional vir a se transformar no decorrer do tempo em um grupo primário, na medida que seus membros vão aprofundando suas relações e descobrindo muitas semelhanças entre si, gerando vínculos afetivos e de complementaridade, fortalecendo a interdependência de seus membros. G rupos que vivenciam essa mudança deslocam sua atividade grupal, anteriormente focada na satisfação de necessidades sistêmicas, para a satisfação de necessidades pessoais. Pudemos verificar essa mudança em um grupo de usuários de uma unidade básica de saúde, que originalmente foram agrupados pela doença comum a todos. 0 objetivo da equipe de saúde, e fundamentalmente da secre taria de saúde que propõe a formação desses grupos nas unidades, era diminuir a possibilidade de situações de risco que poderiam reverter-se em quadros graves para a saúde do usuário, quadros esses que têm um custo financeiro muito elevado para o município. Do mesmo modo, o objetivo dos participantes era aprender a controlar sua doença, para evitar o seu agravamento e suas conseqüências. Em geral, esses grupos têm uma duração curta, com uma média de seis encontros, centrados todos na informação, caracterizando-se como grupos funcionais, do início até o final de sua existência. No entanto, algumas condições objetivas contribuíram para que o grupo 
mudasse radicalmente: ele era formado apenas por mulheres, com faixa etária elevada (acima de 60 anos), moradoras em um bairro de periferia distante de outros bairros e do centro da cidade, com baixa renda. Essas condições implicavam em que essas mulheres tinham pouco acesso a outros locais, viviam essencialmente em casa, no âmbito do espaço privado. Algumas se vinculavam à igreja no bairro e eventualmente iam à unidade de saúde. Em geral suas relações eram restritas ao núcleo familiar e suas atividades eram rotineiras. I nicialmente implementamos neste grupo um processo grupal, que partiu do objetivo comum que identificava naquele momento todos os membros do grupo (a doença), introduzindo já no início do trabalho, além do caráter informativo, um caráter formativo, possibilitando que a experiência pessoal, a história de vida de cada participante passasse a ser um elemento aglutinador e definidor de identificações, assim como a articulação da história individual com a história social de seus membros. Com o passar do tempo, muitas semelhanças são descobertas, não apenas no aspecto restrito à saúde, mas à vida em geral. Com isso, outros componentes vão caracterizando o grupo e vão se formando vínculos afetivos, tendo como conseqüência a mudança da sua atividade principal e, conseqüentemente a mudança da identidade grupal, passando os membros a se preocuparem com a saticfação de suas necessidades pessoais. A necessidade que tinham de se expressarem, de ouvirem e serem ouvidas, de ter um local para onde ir sistematicamente, enfim, de terem uma atividade que rompesse com sua rotina, fez com que essa experiência ganhasse relevância, transformando-se em atividade essencial. A afetividade positiva gerada na experiência grupal, assim como a possibilidade, por menor que seja, das mulheres exercerem controle sobre suas vidas, foram fundamentais para a mudança da identidade grupal.

Essa experiência, entre outras, nos deixou claro que o processo grupal estimula a reflexão individual e coletiva, no sentido de possibilitar que seus membros se conscientizem de sua identidade psicossocial. É o espaço para a problematização do cotidiano, para o desencadeamento de novas relações e vínculos afetivos, para a expressão de opiniões e sentimentos. A partir do grupo torna-se possível identificar as diferenças e as semelhanças nas experiências individuais. Portanto, formação e informação, possibilitam o confronto 
de valores, de experiências, de sentimentos e de informações (senso comum versus conhecimento científico) que gera reflexão e a valorização dos indivíduos, e os impulsionam para a ação. Foram essas condições que facilitaram a transformação do grupo acima citado, em um grupo com uma identidade social, quando sua atividade principal passa a satisfazer as necessidades pessoais de seus membros. Em seguida, o grupo vivenciou uma nova mudança, que 0 levou novamente a se constituir primordialmente como um grupo funcional, porém qualitativamente diferente do momento inicial. Além de sua produção afetivo-emocional dirigir-se para a relação interna, mantendo as relações primárias, o grupo iniciou o movimento de sua externalização social efetiva através de atividades voltadas para a saúde da população de seu bairro, através da produção de jornal popular e a organização de pequenos eventos, com a ampliação da participação para familiares e população em geral.

0 último tipo de grupo apresentado por Martín-Baró é o grupo etrutural queécaracterizado por: comunidade de interesses objetivos (identidade), controle dos meios de produção (poder) e satisfação de interesses de grandes grupos e classes (atividade grupal) ( p. 224).

Embora 0 autor remeta a questão dos interesses de grandes grupos e classes sociais como característica da atividade do grupo estrutural, é importante relembrar que 0 antagonismo das classes sociais, é estruturador da sociedade capitalista contemporânea, e se expressa de modo mais ou menos intenso e explícito em todo e qualquer grupo, mesmo nos grupos primários, cuja organização se realiza a partir de necessidades pessoais.

Esta di vi são em classes sociaisédetal profundidade que influi em todas as relações humanas que se produzem no interior da sociedade. $N$ este sentido se afirma que as relações determinadas pela diferenciação em classes sociais são relações estruturais, já que têm a força de estruturar os esquemas fundamentais da convivência humana .

(M ART ÍN -BARÓ, 1997:76) 
Assim, "relações primárias, funcionais e estruturais não são excludentes, senão que expressam distintos níveis do mesmo processo social" (1997, p.76), processo complexo que implica múltiplos níveis de determinação. Embora a classe social se constitua no nível mais básico de determinação, não significa que seja o nível mais imediato.

\section{PROCESSO GRUPAL E O PODER SOCIAL}

Considerando a concepção exposta anteriormente, como M artín-Baró introduziu a discussão sobre o poder social?

Inicialmente, 0 autor afirma categoricamente 0 fato do poder estar presente em todos os aspectos da vida humana. Acrescenta que na perspectiva da psicologia social pode ser muito mais relevante a análise do papel do poder na vida cotidiana, no dia-a-dia das pessoas, do que se centrar nos acontecimentos excepcionais e não rotineiros (1989, p.92). Visão essa que nos coloca diante da impossibilidade de pensar qualquer relação humana sem o poder e que remeteu M artín-Baró ao trabalho de Foucault sobre o que este chamou de microfísica do poder (1979/1984). N esta perspectiva não existe a possibilidade de colocar de um lado os que têm e de outro aqueles que não têm poder. 0 poder "não é um objeto, uma coisa, mas uma relação" (M ACH AD 0, 1984, p.XIV). Sendo assim, a afirmação cria também a necessidade de romper com o mito de que poder é sinônimo de algo sempre negativo e violento, como é comumente tratado o tema, principalmente no nível do senso comum. Foucault questiona: "Se o poder fosse somente repressivo, se não fizesse outra coisa a não ser dizer não você acredita que seria obedecido?" (p.8), e acrescenta:

0 que faz com que o poder se mantenha e que seja aceito é simplesmente que ele não pesa só como uma força que diz não, mas que de fato de permeia, produz coisas, induz ao prazer, forma saber, produz discurso. D eve seconsiderá-lo como uma redeprodutiva queatravessa todo o corpo social muito mais do que uma instância negativa que tem por função reprimir (p.8). 
$M$ ais do que indicar a relevância de pensar a questão do poder nas relações cotidianas, M artín-Baró (1989) chama a atenção para o fato de que do ponto de vista da psicologia social, um dos aspectos mais importantes do poder "é sua tendência a ocultar-se, inclusive a negar-se como tal, ou seja, como poder, e apresentar-se como exigência natural ou razão social" (p.95). Essa tendência é facilmente demonstrada nos estudos sociológicos, e mesmo psicológicos, sobre a "socialização", quando é definida por vários autores como momento de transmissão de normas e valores predominantes na sociedade aos indivíduos desde o seu nascimento até a fase adulta. Trabalha-se em geral, com uma definição funcionalista, adaptativa do indivíduo, sem considerar a "socialização" como um processo, portanto como sociabilidade, e como tal, contraditório. A "socialização" é um processo histórico, caracterizado sempre por sua concretude temporal e espacial, definido pelas circunstâncias próprias de cada situação histórica. A análise dos processos de socialização "requer examinar como variáveis fundamentais em que sociedade, em que classe social, em que grupo, em que época, em que situação, em que conjuntura tem lugar esses processos" (M ARTíN BARÓ , 1997, p.115). Em síntese, na perspectiva dialética, o processo de socialização envolve três aspectos:

a) a determinação objetiva do contexto da pessoa: 0 indivíduo se insere em uma sociedade, em um grupo social, em uma situação concreta, com possibilidades materiaise sociais bem definidas,

b) a formação histórica dasnecessi dadespessoais segundo a atividadepropiciada, estimulada e exigida pelasre lações sociais, necessidades que se expressam em um determinado estilo de vida;

c) a transmissão de um marco de referência ideológico de normasevaloresassumido psicologi camentecomo atitudesdiante das diversas reali dades. Estemarco ideológi co serve de justificação às necessi dades pessoais e aos interesses da própria classe em que elas encontram assento.

(MARTÍN-BARÓ, 1997: 100) 
Porém, na perspectiva funcionalista, em que esse processo não é compreendido como tal, mas sim como a forma de homogeneização de valores e normas culturais, um aspecto importante é o fato de que preferencialmente a aprendizagem que deve ocorrer na "socialização" do indivíduo seja sutil, para que os indivíduos assimilem as normas e regras sociais como próprias e naturais. D este modo, os indivíduos tornam-se facilmente reprodutores das mesmas, pois não as consideram impostas, e sim como o 'que deve ser', sem vislumbrar qualquer outra possibilidade que não a reprodução. N a verdade, a "socialização" dos indivíduos, é uma das formas mais eficazes de ocultação do poder, que se realiza quotidianamente, que busca manter o controle social sobre o pensar, o sentir e o fazer das pessoas, ou seja, a normatização da ação humana. N este sentido, M artínBaró esclarece que o objeto de seu estudo é "definir e delimitar 0 papel do poder na determinação da ação humana", citando em seguida as duas maneiras pelo qual o poder pode influir no comportamento das pessoas e grupos: uma imediata, impondo uma direção concreta à ação; outra mediata, configurando o mundo das pessoas e determinando os elementos constitutivos dessa mesma ação. As duas formas não são excludentes, e sim inclusivas, além do que, em geral a ação imediata do poder se articula sobre a base de suas determinações mediatas (1989, p.93).

Ao citar as duas formas de influência, o autor não ignora e nem deixa de enfatizar a existência do poder nas relações mais formais e institucionais, no plano jurídico. N essa esfera o poder "é um objeto social de que dispõe o estado como gerente do bem comum e que distribui entre os membros da sociedade a fim de por em execução as exigências e regras do sistema estabelecido" (1989, p.102). Esta idéia traz à tona o pensamento marxiano sobre o poder, que aparece através da discussão sobre a ideologia presente na obra A ideologia alemã , de M arx e Engels (1980), quando afirmam que

O s pensamentos da classe dominante são também, em todasasépocas, os pensamentos dominantes, ou seja, a classe que tem o poder material dominante numa dada sociedade é também a potência dominante espiritual. [...] O sindivíduosque constituem a 
classe dominante possuem entreoutrascoisasuma cons ciência, e é em conseqüência disso que pensam; na medida em que dominam enquanto classe e determinam uma época histórica em toda a sua extensão, é lógi co que esses indi víduos dominem em todos os sentidos, que tenham, entre outras, uma posição dominante como seres pensantes, como produtores de idéas, que regulamentem a produção ea di stri bui ção dos pensamentos de sua época; as suas i déias são, portanto, as idéias dominantes da sua época (p.55-6).

M artín-Baró (1989) apresenta três características essenciais do poder: 1 . Se dá nas relações sociais, o que significa dizer que as relações sociais têm um caráter de oposição e conflito; 2 . Se baseia na posse de recursos, ou seja, "um dos sujeitos da relação, pessoa ou grupo, possui algo que o outro não possui ou possui em menor grau (quantitativo e/ou qualitativo)", o que evidencia uma relação de desequilíbrio em relação a determinado objeto, e "3. Produz um efeito na mesma relação social" (p.97), que se dá tanto sobre o objeto da relação como sobre as pessoas ou grupos relacionados, podendo implicar na "obediência ou submissão de um, o exercício da autoridade ou do domínio do outro. 0 poder configura assim o que fazer de pessoas e grupos" (p.99).

0 poder, ressalta 0 autor, está baseado na posse diferencial de recursos, permitindo que alguns realizem seus interesses, pessoais ou de classe, e os imponha a outros. 0 poder não é um objeto abstrato. Trata-se de "uma qualidade de alguém, pessoa ou grupo, na relação com outras pessoas ou grupos. [...] 0 poder constitui, por conseguinte, um fenômeno social, não meramente individual" (M ARTÍN -BARÓ, 1989, p.97).

Q uando 0 autor diz que o poder é baseado na posse diferencial de recursos engloba aqui os mais distintos recursos, entre eles: capacidade técnica, científica ou profissional; econômico; moral. Assim, os grupos mais poderosos serão aqueles que disponham de todo tipo de recursos: materiais, culturais e pessoais. 
Entre os recursos pessoais, a afetividade não foi ressaltada por M artín-Baró. N o entanto, tanto a afetividade considerada positiva quanto a negativa pode permear as relações e produzir um efeito sobre elas. Partindo da idéia de que a organização grupal envolve as atividades produzidas e também as produções afetivo-emocionais, que dirigem formal e informalmente o clima das relações entre os membros e entre estes e a atividade, não é possível desconsiderar a importância da afetividade nas relações grupais, seja no sentido de ampliar a união como para ameaçar a sua existência. 0 vínculo de amizade entre membros de um grupo pode facilitar algumas relações e decisões coletivas (em geral isso ocorre), como, por exemplo, maior atenção ao que esta pessoa diz, defesa de suas propostas etc. Por outro lado, essa relação de poder pode ser exercida pelo sentimento negativo que um membro gera sobre outro(s). U ma relação baseada no medo pode gerar a submissão de um e o domínio do outro. U m exemplo disso é quando o professor, ou mesmo um colega de classe, que se considera o depositário do saber, desqualifica as dúvidas de seus alunos ou colegas, criando um clima de mal-estar, desmotivando as pessoas a se manifestarem.

O utro aspecto relevante apresentado pelo autor é que "as pessoas e os grupos mantém entre si multiplicidade de relações que envolvem aspectos muito diversos da existência e se apoiam em diferentes recursos" (1989, p.101), implicando no fato de que quem domina em uma relação pode ser dominado em outra. Pudemos observar claramente esse fenômeno na atuação dos Conselhos de Saúde (municipal e gestores). No âmbito do conselho municipal, pudemos verificar que a relação de poder realizava-se baseada na posse de dois tipos de recursos: a autoridade e o saber. O s representantes dos órgãos municipais e estaduais de saúde, os profissionais da saúde com nível universitário, expressavam suas opiniões continuamente, utilizando linguagem técnica, pouco acessível aos repre sentantes de usuários. M uitos destes se intimidavam perante a autoridade e a capacidade discursiva dos técnicos, limitando-se a votar as propostas. O utros tentavam participar, colocando suas dúvidas ou as necessidades da população, mas eram imediatamente cortados, sem que sua manifestação ganhasse espaço, ou mesmo um pouco de atenção dos demais. Em geral, observa-se a impaciência dos "cul- 
tos" em ouvir e decodificar o sentido da fala daqueles que não tiveram a possibilidade de exercitar-se politicamente. No entanto, esse mesmo representante que se subordina ao poder do outro nesse espaço, muitas vezes vai ser aquele que detém o poder no espaço da associação de moradores, no conselho de saúde da unidade básica do seu bairro etc. 0 fato do indivíduo circular por outras instâncias, ouvir o que outros dizem sobre a saúde, faz com que possa ter informações privilegiadas em relação aos outros moradores do bairro. Além disso, pode-se observar também a apropriação do modelo de poder vivenciado no âmbito mais amplo de atuação, reproduzindo-o nas instâncias mais imediatas e cotidianas.

N esse momento é importante retomar os parâmetros utilizados por M artín-Baró para a análise do processo grupal: a identidade, o poder e a atividade grupal. Como colocamos anteriormente, estes não podem ser pensados isoladamente, mas intrinsecamente articulados e influindo um no outro. $\mathrm{N}$ ão se pode perder de vista sua natureza histórico-social.

Ao refletir sobre o processo grupal, na sua concreticidade, tere mos uma visão mais clara de como as relações grupais e de poder estão organizadas, o que poderá contribuir para o resgate dos objetivos e finalidades da atividade grupal. Além disso, considerando que grande parte da prática profissional do psicólogo, principalmente numa perspectiva psicossocial, envolve o trabalho com pequenos grupos, a abordagem da questão do poder passa a ter papel fundamental. N este sentido, o contato com a produção de M artín-Baró é essencial e pode contribuir incisivamente no nosso trabalho cotidiano.

\section{REFERÊNCIAS}

CANETTI, E. (1960) Elementos do poder. In:_-_. M assa e poder. Trad. Sérgio Tellaroli. São Paulo: Companhia das Letras, 1995. P.279333.

FOU CAU LT, M. M icrofísica do poder. O rganização e tradução de Roberto M achado. 4a․ed., Rio de Janeiro: Graal, 1984. 
LANE, S.T. 0 processo grupal. In: ___ e CODO, W. (O rg.). Psicologia social - o homem em movimento. SP: Brasiliense, 1984. p. 78-98.

M ACHAD O, R. Introdução. Por uma genealogia do poder. In: FOU CAU LT, M. M icrofísica do poder. O rganização e tradução de Roberto M achado. 4a.ed., Rio de Janeiro: Graal, 1984. p. VII-XXIII. M ART ÍN -BARÓ, I. (1983) Accion eideología. Psicología social desde Centroamérica. 8a ed., San Salvador: U CA Ed., 1997. (Colección Textos Universitarios, Serie Psicología, 1)

M ART ÍN-BARÓ, I. Sistema, grupo y poder. Psicología social desde Centroamérica II. San Salvador: U CA Ed., 1989. (Colección Textos Universitarios, 10)

M ARX, K. e EN GELS, F. (1845) A ideologia alemã. Trad. Conceição Jardim e Eduardo L. Nogueira. Lisboa/São Paulo, M artins Fontes, 1980.

Sueli Terezinha Ferreira M artinsé D outora em Psicologia Social, docente do Programa de PósG raduação em Educação para Ciência da U N ESP - Bauru e do D epartamento de N eurologia e Psiquiatria.

UN ESP- Botucatu, Brasil.

E-mail: sftm@fnb.unesp.br

Sueli Terezinha Ferreira M artins

Processo G rupal e a questão do poder em M artín-Baró

Recebido: 20/6/2002

1a revisão: 12/5/2003

Aceite final: 14/7/2003 